\title{
Snow grain-size profiles deduced from microwave snow emissivities in Antarctica
}

\author{
Ludovic BRUCKER, Ghislain PICARD, Michel FILY
}

\author{
Laboratoire de Glaciologie et Géophysique de I'Environnement, CNRS/Université Joseph Fourier - Grenoble I, \\ 54 rue Molière, BP 96, 38402 Saint-Martin-d'Hères Cedex, France \\ E-mail: Ibrucker@lgge.obs.ujf-grenoble.fr
}

\begin{abstract}
Spaceborne microwave radiometers are an attractive tool for observing Antarctic climate because their measurements are related to the snow temperature. However, the conversion from microwave emission to snow temperature is not simple and strongly depends on the emissivity through snow properties. This difficulty in predicting the snow property profile for Antarctic conditions is the main bottleneck in the retrieval of accurate climate information from microwave radiometers. We attempt to explain the vertically polarized emissivity at 19.3 and $37 \mathrm{GHz}$ derived from brightness temperatures acquired by the Special Sensor Microwave/Imager (SSM/I) and physical temperature from the ERA-40 re-analysis. In Antarctica the snow emissivities at 19.3 and $37 \mathrm{GHz}$ are nearly equal, although a decrease with frequency is expected. To explain this, we consider various profiles of snow grain size and density and predict their emissivity using a dense-medium radiative transfer (DMRT) model. The results show that the emissivities cannot be explained by constant profiles of grain size and density. Heterogeneous snowpacks need to be considered. We first test random variations of snow density and grain radius with depth and then monotonic and continuous variations in the snow grain radius. In both cases, we show that an overall increase of the snow grain radius with depth is required to match the observed emissivity in Antarctica. In addition, two parameters characterizing the snow grain profiles are retrieved and compared with (1) in situ measurements of grain size at various locations in East Antarctica, (2) grain size estimated using visible spaceborne radiometers and (3) a semi-empirical relationship for grain growth.
\end{abstract}

\section{INTRODUCTION}

High-latitude regions of the Earth play an important role in the climate system and are critical for surveying climate change (Lemke and others, 2007), but acquiring accurate observations in these remote regions remains challenging. In Antarctica, accurate observations are crucial to provide the current state and trends of the climate with confidence. Such observations can be obtained from meteorological stations and spaceborne sensors. Investigation of Antarctic climate change using only ground-based meteorological observations is limited by the sparsity of the stations (Turner and others, 2005). In contrast, remote sensing provides synoptic estimates of climatic variables such as surface temperature (Comiso, 2000; Shuman and Stearns, 2001; Schneider and Steig, 2002; Shuman and Comiso, 2002; Schneider and others, 2004; Steig and others, 2009), snow accumulation (Vaughan and others, 1999; Arthern and others, 2006) and the extent and duration of surface melting (Picard and others, 2007). Remote sensing also allows estimation of glaciological properties such as snow grain size at the surface (Scambos and others, 2007), snow thermal diffusivity (Koenig and others, 2007) and surface roughness (Long and Drinkwater, 2000).

In the microwave range, radiometers measure the thermal radiation emitted by the snowpack (expressed as brightness temperature). Brightness temperature is, to a first approximation, the product of snow temperature and emissivity (Zwally, 1977). Retrieval of accurate snow temperature is possible in principle, but is currently limited by uncertainties in the snow emissivity. Most factors influencing the snow emissivity in the microwave range are identified (Surdyk, 2002; Grody, 2008). Snow wetness is the dominant factor but its effect is limited to coastal regions in Antarctica (Picard and Fily, 2006). In regions where snow is dry, grain size and density have the strongest influence (e.g. Tsang and others, 2000b). This suggests that knowledge of snow grain size and its variations with depth is required to interpret microwave data (Zwally, 1977). The emissivity has little dependence on surface roughness (azimuth angle) (Rémy and Minster, 1991; Shuman and others, 1993; Long and Drinkwater, 2000) or snow temperature (Surdyk, 2002). The vertical variations of density due to stratification are especially important for the horizontal polarization (Mätzler and others, 1984; West and others, 1994, 1996). Moreover, the emissivity depends on the observation configuration, i.e. the frequency and incidence angle (e.g. Prigent and others, 2000).

At microwave frequencies, dry snow is a low-loss medium and the radiation penetrates deep into the snowpack. Penetration of microwaves in snow is limited by losses due to scattering and absorption and, hence, is frequency dependent. In Antarctica, penetration depth is $0.1-2 \mathrm{~m}$ at $37 \mathrm{GHz}$, and $1-7 \mathrm{~m}$ at $19 \mathrm{GHz}$ for snow grain sizes between 1 and $0.2 \mathrm{~mm}$ (e.g. Sherjal and Fily, 1994; Surdyk, 2002; Macelloni and others, 2007; Picard and others, 2009).

Modeling the emissivity from measured or estimated snow properties at various locations in Antarctica has been addressed in several studies. Zwally (1977) and Comiso and others (1982) computed the $19 \mathrm{GHz}$ emissivity at four sites, using radiative transfer models and measured snow grainsize profiles. The influence of snow grain scattering and reflection by density stratification on microwave emission at frequencies less than $6.6 \mathrm{GHz}$ was studied at Plateau Station (West and others, 1994), using a multilayered model based on dense-media radiative transfer (DMRT) theory (Tsang and 
others, 2000a). The conclusion of that study suggests that emissivity at low frequencies $(\leq 10 \mathrm{GHz})$ depends both on snow grain scattering and reflection processes, whereas at higher frequencies the emissivity is dominated by snow grain scattering. The emissivities at vertical and horizontal polarizations were computed using a model based on the strong-fluctuation theory (Stogryn, 1986) and driven by random profiles of snow properties at three different sites (Surdyk and Fily, 1995). The snowpack was assumed isothermal, whereas snow density and snow grain-size profiles were defined by the superposition of a linear increase with depth and random fluctuations. These snowpacks were used to reproduce the observed frequency dependence (i.e. the spectral signature) as well as the differences between the two polarizations. In Antarctica, studies focusing on modeling observed brightness temperature time series from measured snow properties have been addressed only at Dome C by Macelloni and others (2007) and Brucker and others (in press) using DMRT models.

In contrast, modeling the emissivity at the Antarctic scale has received little attention because measured snow properties are too sparse with respect to the large spatial variations of the snowpack properties. The objective of the present study is to explain large-scale emissivity variations in Antarctica by electromagnetic modeling. To overcome the lack of measurements, our approach consists of numerically estimating the snow properties compatible with the observed emissivities. Our particular aim is to investigate and explain the flat spectral signature observed over most of the Antarctic continent. Grody and Basist (1997) and Rosenfeld and Grody (2000) classified snow microwave spectral signatures as either 'normal' or 'anomalous' spectra, using multi-frequency measurements from spaceborne passive microwave sensors. The 'normal' spectrum is a decrease of the emissivity with increasing frequency (Rosenfeld and Grody, 2000) due to the dominant effect of scattering by snow grains that increases with increasing frequency. The 'anomalous' snow spectrum is the opposite trend and was observed (1) in stratified Alpine snow between the $85 \mathrm{GHz}$ channel and the 19 or $37 \mathrm{GHz}$ channels (Mätzler and Schanda, 1982), (2) in central Siberia at the end of the winter (Rosenfeld and Grody, 2000) and (3) in southern Greenland (Grody and Basist, 1997). We note that, over most of Antarctica, emissivities calculated from the brightness temperatures acquired by the Special Sensor Microwave/Imager (SSM/I) at 19.3 and $37 \mathrm{GHz}$ are very close, compared with other regions. The signature is intermediate between 'normal' and 'anomalous', and is called 'flat' hereafter. The signature is even 'anomalous' over a few areas, i.e. the emissivity is larger at $37 \mathrm{GHz}$ than at $19 \mathrm{GHz}$.

In the present paper, we explain the vertically polarized emissivities at 19.3 and $37 \mathrm{GHz}$ observed in Antarctica, using electromagnetic modeling based on DMRT theory. The model is driven by various homogeneous and heterogeneous snowpacks. The heterogeneous snowpacks are defined with either random variations or monotonic and continuous variations with depth. In the latter case, the two parameters characterizing the snow grain profile (i.e. the snow grain radius near the surface and the vertical grain-size gradient) are retrieved for each $25 \mathrm{~km} \times 25 \mathrm{~km}$ pixel in the Antarctic dry zone. These parameters are compared with in situ grainsize measurements, visible remote-sensing estimates of grain size and a simple snow metamorphism relationship between the snow grain-size growth and key climatic properties (air temperature and snow accumulation).
We consider only two frequencies (19.3 and $37 \mathrm{GHz}$ ) and the vertical polarization. Other frequencies available on SSM/I (22.2 and $85.5 \mathrm{GHz}$ ) are sensitive to external factors of the snowpack structure such as the atmospheric water vapor $(22.2$ and $85.5 \mathrm{GHz})$ or the surface state $(85.5 \mathrm{GHz})$. The vertical polarization is selected because SSM/I brightness temperatures are acquired at a $53.1^{\circ}$ incident angle (Hollinger and others, 1990), which is close to Brewster's angle and is, thus, less affected by surface reflection and stratification than the horizontal polarization (Rémy and Minster, 1991; West and others, 1996). The region of interest is limited to the dry-snow zone (Picard and Fily, 2006) in order to avoid the complex influence of liquid water or ice layers (e.g. Magand and others, 2008). Lastly, our study deals with annual mean emissivities, computed from annual mean brightness temperatures and air temperature over the period 1987-2002 (the calculation is detailed below). By this calculation, the variations of the azimuth angle of observation with respect to the main roughness direction (Long and Drinkwater, 2000) are moderated.

In section 2, we present the calculation of the emissivity from SSM/I observations and describe our electromagnetic multi-layered (ML) model (DMRT-ML). In section 3, we present the spatial variations and the spectral signature of the emissivity in Antarctica and attempt to explain these features with the DMRT-ML model considering homogeneous and heterogeneous snowpacks. In section 4 , snow grain radius profile parameters are retrieved and briefly analyzed at the Antarctic scale. These results are compared and discussed with respect to in situ and optical spaceborne estimates of grain size, as well as with the prediction from a simple metamorphism relationship driven by climate models. Our conclusions are reported in section 5.

\section{METHODS}

\subsection{Microwave data}

Brightness temperatures were extracted from the US Defense Meteorological Satellite Program (DMSP) SSM/I Daily Polar Gridded Brightness Temperature dataset (Version 2), distributed at a spatial resolution of $25 \mathrm{~km} \times 25 \mathrm{~km}$ by the US National Snow and Ice Data Center. The dataset includes the 19.3 and $37 \mathrm{GHz}$ channels, at vertical polarization, acquired by the SSM/I on board the DMSP F8, F11 and F13 missions.

Even though the atmosphere over Antarctica is dry and cold, it affects both the 19 and $37 \mathrm{GHz}$ frequencies, but with different amplitudes. The spectrum of emissivity at the top of the atmosphere is different from that at the surface. Hence, to analyze the electromagnetic radiation solely emitted by the snowpack and then to relate the spectrum to snow properties, it is more accurate to correct the top-of-atmosphere brightness temperatures. Top-of-snowpack emissivities are computed from the top-of-atmosphere observations assuming a nonscattering atmosphere (Rosenkranz, 1998; Tedesco and Wang, 2006; Picard and others, 2009) using terms averaged over the period 1987-2002 and

$$
e_{\text {obs }}=\frac{T_{\mathrm{B}}^{\text {SSMI }}-T_{\mathrm{B}}^{\text {atmo }} \uparrow-\tau\left(T_{\mathrm{B}}^{\text {atmo }} \downarrow+\tau T_{\mathrm{B}}^{\text {cosmic }}\right)}{\tau T_{\text {air }}-\tau\left(T_{\mathrm{B}}^{\text {atmo }} \downarrow+\tau T_{\mathrm{B}}^{\text {cosmic }}\right)} .
$$

$T_{\mathrm{B}}^{\mathrm{SSMl}}$ is the averaged brightness temperature measured by SSM/I over the period 1987-2002 and $T_{\text {air }}$ is the averaged air temperature extracted from the European Centre for Medium- 
Range Weather Forecasts (ECMWF) ERA-40 re-analysis (Uppala and others, 2005) for the same period. The transmittance, $\tau$, and the upward $\left(T_{\mathrm{B}}^{\text {atmo }} \uparrow\right)$ and downward $\left(T B^{\text {atmo }} \downarrow\right)$ atmospheric brightness temperatures are calculated from the atmospheric attenuation computed using Rosenkranz's model (1998) driven by the temperature and moisture profiles from the ERA-40 re-analysis. $T_{\mathrm{B}}^{\text {cosmic }}$ is the cosmic background brightness temperature at microwave wavelengths (2.75K).

The top-of-snowpack emissivity calculated using Equation (1) is $\sim 0.007$ higher at $19.3 \mathrm{GHz}$, and 0.018 higher at $37 \mathrm{GHz}$, than that calculated at the top of the atmosphere when neglecting the atmosphere (Picard and others, 2009). Any error in the air temperature predicted by the ERA-40 reanalysis (estimated as $\sim 2 \mathrm{~K}$ at Dome C; Bromwich and Fogt, 2004; Picard and others, 2009) has a significant impact at all frequencies on the absolute value of emissivity (0.01). However, since the same air temperature is used to calculate the emissivities at both frequencies, the uncertainty in this meteorological variable has a moderate influence on the relative difference between emissivities. Hereafter, all emissivities are at vertical polarization and, for clarity, the emissivities estimated from Equation (1) are called observed emissivities.

\subsection{Microwave emission modeling}

The electromagnetic model used in this study is based on the radiative transfer equation and dense-media theory (Tsang and Kong, 2001). DMRT theory has been extensively used to study active and passive remote sensing of seasonal and perennial snow (Tsang and others, 2000a, 2007; Macelloni and others, 2001,2007; Tedesco and others, 2006; Grody, 2008; Liang and others, 2008) and snow over sea ice (West and others, 1993).

Snow is assumed to be a medium composed of ice spheres. The effective dielectric constant of the medium is solved using the first-order quasi-crystalline approximation coherent potential (QCA-CP) and the Percus-Yevick pair distribution for nonsticky particles (i.e. particles which do not form aggregates) (Tsang and Kong, 2001). This computation is valid in the limit of low frequency and/or small particle size (i.e. $2 \pi r / \lambda<1$ with $r$ the sphere radius and $\lambda$ the wavelength). The QCA-CP is in agreement with numerical solutions of Maxwell equations in three-dimensional simulations (NMM3D-DMRT) up to a fractional volume of $\sim 30 \%$, and deviates above (Liang and others, 2006; Tsang and others, 2008). QCA-CP may underestimate the extinction coefficient both at 19 and $37 \mathrm{GHz}$ for fractional volumes more than $30 \%$, as does QCA. The impact is an overestimated retrieved grain size in regions of high density.

We developed a multilayered DMRT model (DMRT-ML) able to calculate brightness temperature and emissivity of a layered snowpack. Each layer is characterized by thickness, snow grain size (sphere radius), density and temperature. The emission and propagation of radiation through the snowpack are computed for 32 directions using the discreteordinate radiative transfer (DISORT) method (Jin, 1994). This method accounts for multiple scattering between layers. Modeled snow layers are much thicker than the wavelength (e.g. $1.55 \mathrm{~cm}$ at $19.3 \mathrm{GHz}$ ), so interferences are not considered. The snow/air interface and the interfaces between the layers are assumed to be smooth.

To confirm our results computed with DMRT-ML and presented in section 3, emissivities were also computed with the Microwave Emission Model of Layered Snowpacks, MEMLS (Wiesmann and Mätzler, 1999), Version 3. MEMLS is a semi-empirical model and differs from DMRT-ML in the way it calculates (1) the scattering coefficient (i.e. the improved Born approximation (Mätzler, 1998; Mätzler and Wiesmann, 1999) instead of the DMRT theory) and (2) the propagation of radiation through the snowpack (i.e. the sixflux theory instead of the DISORT method). In addition in MEMLS, the snow grain size is quantified by the correlation length (Mätzler, 2002).

\section{RESULTS}

\subsection{Emissivities derived from observations}

The observed vertically polarized emissivities at frequencies of 19.3 and $37 \mathrm{GHz}$ derived from Equation (1) range between 0.64 and 0.98 in the Antarctic dry-snow zones (Fig. 1a and b). The spatial variations are similar at the two frequencies. The emissivity reaches its highest values in Marie Byrd Land, West Antarctica (Fig. 2) at both frequencies ( 0.97). In Wilkes Land, the emissivity tends to decrease with increasing altitude (from 0.95 to 0.90), whereas the emissivities in Dronning Maud Land are near uniform, with values similar to those observed on the East Antarctic plateau $(\sim 0.83)$. Two regions are characterized by very low emissivities: of $\sim 0.70-0.72$, in the sector $0-30^{\circ} \mathrm{E}$ (Dronning Maud Land) and $0.65-0.70$ in the sector $100-150^{\circ} \mathrm{E}$ (south of $75^{\circ} \mathrm{S}$ in Victoria Land). Snow dunes and glazed surfaces have been reported in those regions (Fahnestock and others, 2000; Frezzotti and others, 2002a, b).

Throughout this paper, plots of the emissivity at $37 \mathrm{GHz}$ as a function of the emissivity at $19.3 \mathrm{GHz}$ (both at vertical polarization) are presented in order to visualize the spectral signature. This visualization is called $19-37 \mathrm{GHz}$ space hereafter.

The observed emissivities calculated using Equation (1) are presented in $19-37 \mathrm{GHz}$ space in Figure 3b. Every dot corresponds to one $25 \mathrm{~km} \times 25 \mathrm{~km}$ pixel in the Antarctic dry-snow zone. The most remarkable feature in Figure $3 \mathrm{~b}$ is that the observed emissivities are correlated and relatively close to the $1: 1$ line; the difference between the emissivities at the two frequencies does not exceed 0.05. These differences in emissivities are smaller than those observed with a surface-based radiometer between 19 and $37 \mathrm{GHz}$ over a seasonal snowpack. Measured differences in emissivities were $>0.1$ for deep snow, $\sim 0.13$ for a snowpack of intermediate depth and a snowpack with a bottom crust, and up to 0.25 for a snowpack with a thick crust (Mätzler, 1994, fig. $1 \mathrm{i}, \mathrm{j}, \mathrm{m}$ and $\mathrm{n}$ ).

The $1: 1$ line is a rigorously frequency-independent spectrum. 'Anomalous' spectra are located above the $1: 1$ line and 'normal' spectra are well below it. We call the Antarctic characteristic spectrum a flat spectrum. A limited number of dots ( $\sim 5 \%$ of the dry-snow zones) correspond to 'anomalous' spectra (Fig. 2).

In the next three subsections we aim to explain the Antarctic flat spectrum by electromagnetic modeling. We first calculate the emissivity of homogeneous snowpacks and show that this configuration is incompatible with the observations. We then consider layered snowpacks and test two different kinds of profiles: (1) random variations of grain radii and density, and (2) monotonic and continuous variations. 

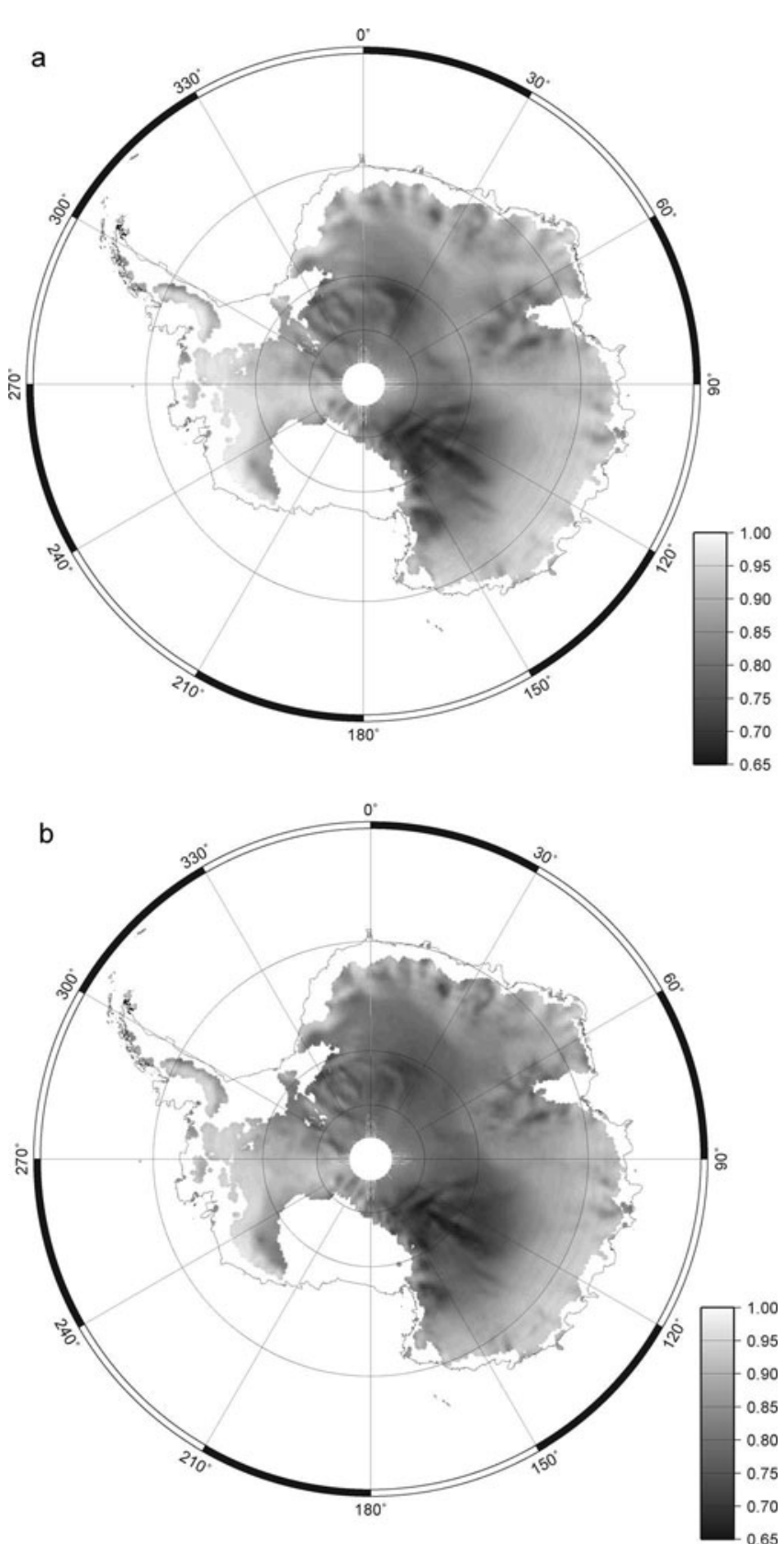

Fig. 1 Maps of observed emissivities at vertical polarization (a) $19.3 \mathrm{GHz}$ and (b) $37 \mathrm{GHz}$ computed using Equation (1). Regions where melt occurred are masked (in white). No data are available south of $87.8^{\circ}$

\subsection{Homogeneous snowpack}

Figure 3a shows the emissivity of a homogeneous snowpack (i.e. a semi-infinite layer whose snow properties are constant) as a function of the snow grain radius, at 19.3 GHz (continuous curve) and $37 \mathrm{GHz}$ (dashed curve). The calculation is performed with DMRT-ML and a snow density of $350 \mathrm{~kg} \mathrm{~m}^{-3}$.

The emissivity decreases with both increasing snow grain radius and increasing frequency (Fig. 3a). The decrease of emissivity with increasing snow grain radius is due to an increase in scattering that prevents the thermally emitted radiation from escaping the snowpack. It is due to Rayleigh scattering. Hence, for a given grain radius, scattering efficiency is greater at $37 \mathrm{GHz}$ than at $19.3 \mathrm{GHz}$. As an example, the difference between the emissivities at 19.3 and

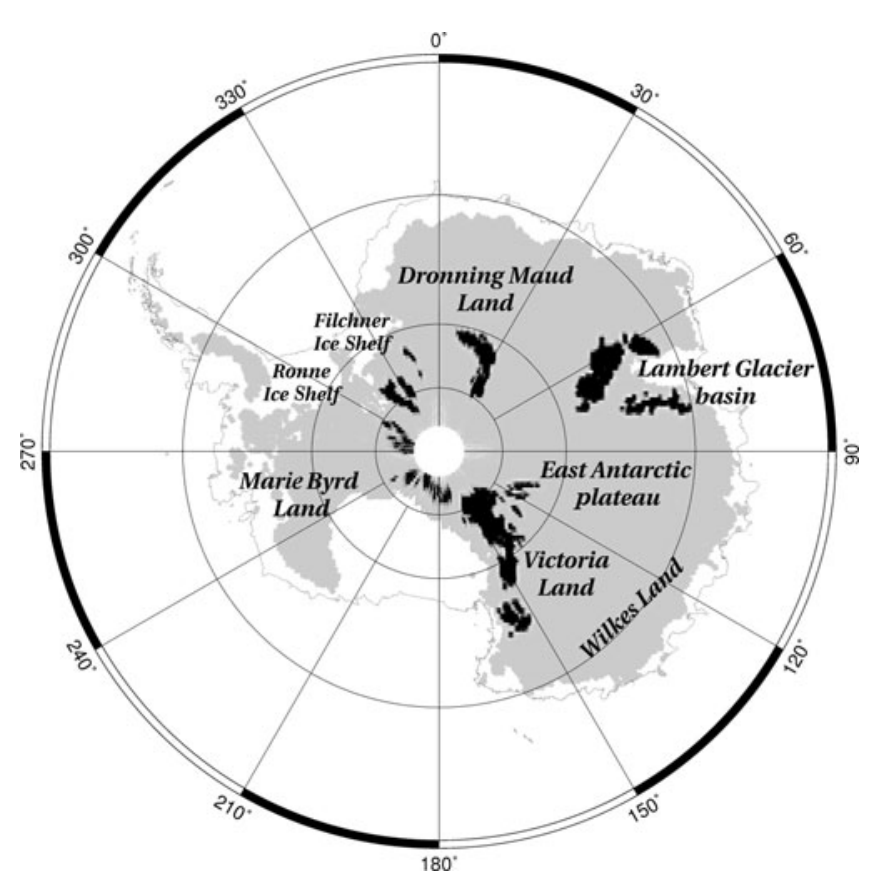

Fig. 2. Map of regions where the snowpack emits with an 'anomalous' snow spectrum (dark zones), i.e. the emissivity is higher at $37 \mathrm{GHz}$ than at $19.3 \mathrm{GHz}$.

$37 \mathrm{GHz}$ is $\sim 0.08$ for a snow grain radius of $0.5 \mathrm{~mm}$ and larger for larger snow grains (e.g. up to 0.18 for a sphere radius of $0.9 \mathrm{~mm}$ ).

The same results are presented in a different way, in 19-37 GHz space (Fig. 3b), in order to emphasize the spectral signature. Whatever the model (DMRT-ML or MEMLS) and whatever the density (300 or $400 \mathrm{~kg} \mathrm{~m}^{-3}$ ), the modeled emissivities of a homogeneous snowpack have much higher values at $19.3 \mathrm{GHz}$ than at $37 \mathrm{GHz}$ and are located far below the $1: 1$ line in the $19-37 \mathrm{GHz}$ space. This spectral behavior is the 'normal' spectrum of seasonal snow in most regions on Earth (Mätzler, 1994). From Figure 3b, it is clear that the observed and modeled emissivities encompass different regions in the $19-37 \mathrm{GHz}$ space. We conclude that the hypothesis of a homogeneous snowpack is inadequate to explain the emissivities at both 19.3 and $37 \mathrm{GHz}$ frequencies in Antarctica.

\subsection{Randomly generated heterogeneous snowpack}

The Antarctic snowpack is known to be structured and usually presents large and discontinuous variations of snow grain radii and densities (e.g. Alley, 1987, 1988) over the depth from which the radiation emanates, i.e. $0.1-2 \mathrm{~m}$ at $37 \mathrm{GHz}$ and $1-7 \mathrm{~m}$ at $19 \mathrm{GHz}$ for snow grain sizes ranging typically between 1 and $0.2 \mathrm{~mm}$ (Sherjal and Fily, 1994; Surdyk, 2002; Macelloni and others, 2007; Picard and others, 2009). This suggests a calculation of the emissivity based on randomly generated heterogeneous snowpacks.

In real snowpacks, the grain size and density vary simultaneously with depth. However, no clear relationship is available for Antarctic snow. Snowpacks considered in the following text are an idealization required for the tractability of the problem.

We first consider random variations of snow density with a fixed snow grain radius $(0.7 \mathrm{~mm})$. For this fixed-grain radius, 25000 random snowpacks composed of 15 layers are generated by randomly selecting the thickness of each 

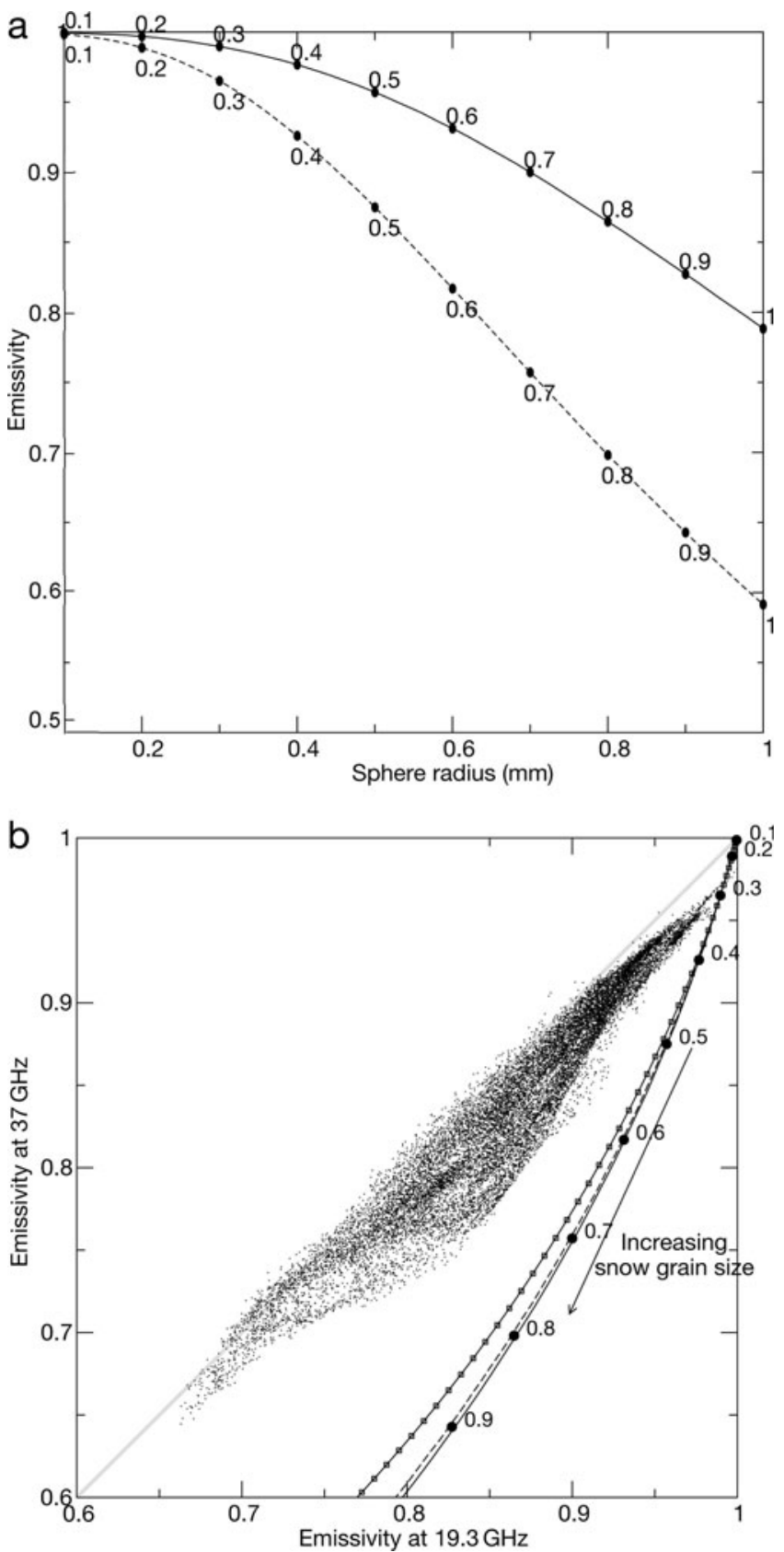

Fig. 3. (a) Modeled vertically polarized emissivities for homogeneous snowpacks as a function of snow grain radius at $19.3 \mathrm{GHz}$ (continuous curve) and $37 \mathrm{GHz}$ (dashed curve). Grain radius (mm) is annotated on the curves. The density is $350 \mathrm{~kg} \mathrm{~m}^{-3}$. (b) Emissivity observed in the Antarctic dry-snow zone at $37 \mathrm{GHz}$ as a function of the emissivity at $19.3 \mathrm{GHz}$ (dots). Same for modeled emissivities (curves) for homogeneous snowpacks with grain radius ranging from 0.1 to $1 \mathrm{~mm}$. The different curves correspond to two DMRT$\mathrm{ML}$ calculations with snow density of $300 \mathrm{~kg} \mathrm{~m}^{-3}$ (continuous curve) and $450 \mathrm{~kg} \mathrm{~m}^{-3}$ (dashed curve) and to one MEMLS calculation with snow density of $300 \mathrm{~kg} \mathrm{~m}^{-3}$ (continuous curve with squares).

layer, then normalizing so that the total depth is $10 \mathrm{~m}$. Thus, the layer thickness ranges between 0.1 and $2.5 \mathrm{~m}$. The density in each layer is drawn from a uniform distribution between 200 and $500 \mathrm{~kg} \mathrm{~m}^{-3}$. Finally, the emissivities for each of the 25000 realizations are calculated with DMRT$\mathrm{ML}$ and are reported in Figure 4.

The results indicate that density variations have a moderate effect on the vertically polarized emissivities and

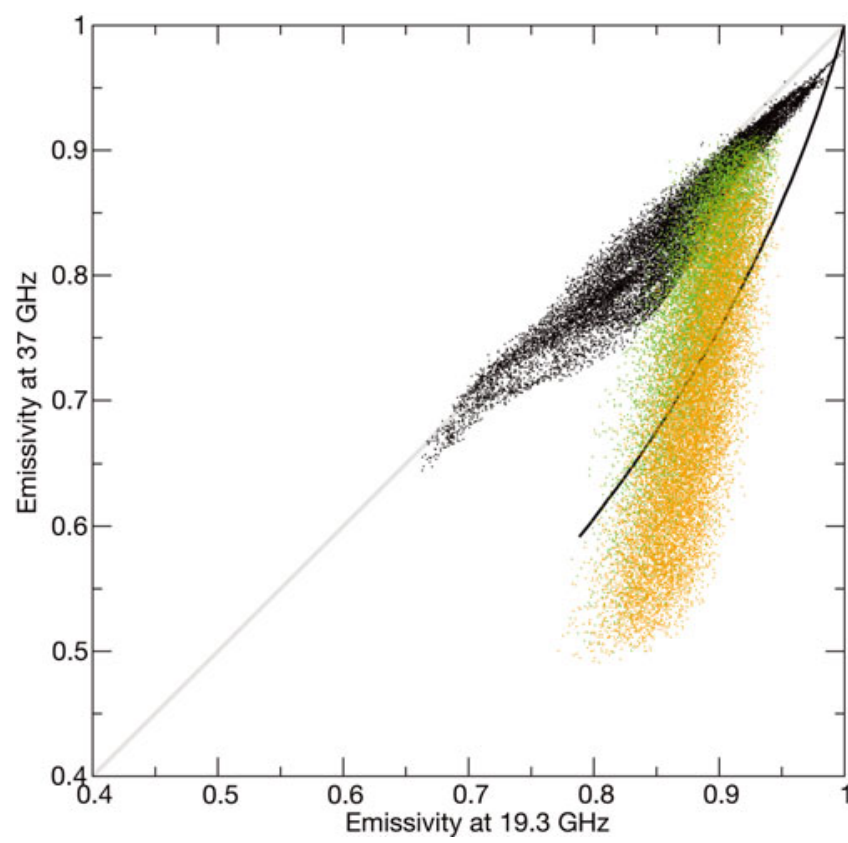

Fig. 4. Modeled emissivities at vertical polarization for snowpacks with a fixed snow grain radius $(0.7 \mathrm{~mm})$ and 15 layers with random variations of snow density in the first $10 \mathrm{~m}$. Snowpacks were classified in two categories depending on the increase (orange color) or decrease (green color) of the density trend with depth. The curve represents the emissivity of homogeneous snowpacks (DMRT$\mathrm{ML}$ calculation, grain radius of $0.1-1 \mathrm{~mm}$; Fig. 3). Black dots are the observed emissivities.

that most generated snowpacks present a 'normal' spectrum, similar to that of homogeneous snowpacks. Similar results are obtained for a fixed snow grain radius of $0.3 \mathrm{~mm}$. Only a limited number of the modeled emissivities overlap the region of observed emissivities in $19-37 \mathrm{GHz}$ space. However, in these cases, the density profile always decreases with increasing depth. This is unrealistic (e.g. Li and Zwally, 2004) and leads to the conclusion that density variations alone do not explain the observed emissivities at the Antarctic scale.

Second, we consider random variations of snow grain radius (drawn from the uniform distribution 0.1-1.4 $\mathrm{mm}$ ) with a fixed snow density $\left(350 \mathrm{~kg} \mathrm{~m}^{-3}\right)$. Figure 5 presents the results in $19-37 \mathrm{GHz}$ space. The region covered by the modeled emissivities is wide, due to the strong sensitivity of the emissivity to grain size (Zwally, 1977; Surdyk, 2002; Grody, 2008). The region is even wider than the observed emissivities, which indicates that only a subset of the generated snowpacks matches the observations. To investigate the peculiarity of these snowpacks, we classify the 25000 generated snowpacks depending on whether the grain radius increases or decreases with increasing depth. The contours shown in Figure 5 enclose the snowpacks in each of these two categories. The snowpacks with a negative grain-size gradient (i.e. a decrease in snow grain radius with increasing depth) have emissivities located near or below the curve of the homogeneous snowpacks (i.e. present 'normal' snow spectra). In contrast, modeled emissivities located near the observed emissivities in 19-37 GHz space correspond mostly to snowpacks with a positive grain-size gradient (i.e. an increase in snow grain radius with increasing depth). For example, to match the typical observed emissivities in Wilkes Land $(0.92$ and 0.90 at 
19.3 and $37 \mathrm{GHz}$, respectively), the snow grain radius increases from $0.3 \mathrm{~mm}$ in the $0-1 \mathrm{~m}$ layer to $\sim 0.6 \mathrm{~mm}$ in the 3-4 m layer.

This result shows that the majority of the modeled emissivities near or above the 1:1 line correspond to snowpacks with a positive grain-size gradient. We conclude that the flat spectrum of the snow in Antarctica mainly results from the fact that snow grain size increases with increasing depth, which is realistic.

\subsection{Heterogeneous snowpack with a monotonic and continuous increase in snow grain size}

Though random variations of snow properties seem realistic with respect to measured profiles in the numerous snow pits dug in Antarctica, they may not be representative of the snowpack at the satellite field of view (brightness temperature products are distributed at a spatial resolution of $25 \mathrm{~km}$ $\times 25 \mathrm{~km}$ ), and their characteristics are statistically difficult to interpret. Here we consider a different approach with idealized snowpack profiles, which are characterized by two simple parameters.

The profiles are assumed to be monotonic and continuous with snow grain-radius profiles given by analytical relationships. We consider three different parameterizations of snow grain-radius profiles, $r(z)$ (with $z$ pointing downward from the surface to $10 \mathrm{~m})$, so that

$$
r^{n}=r_{\text {near surf }}^{n}+z Q_{n}
$$

where $r_{\text {near surf }}$ is representative of a mean snow grain radius in the upper part of the snowpack (see section 4), $n$ is the growth exponent (equal to 1,2 or 3) and $Q_{n}$ is the snow grain-size gradient. $Q_{n}$ is positive so that grain radius $(n=1)$, grain surface $(n=2)$ and grain volume $(n=3)$ increase linearly as a function of depth. The emissivities are calculated assuming a constant snow density of $350 \mathrm{~kg} \mathrm{~m}^{-3}$.

The three exponents $(n=1,2$ and 3$)$ result in the emissivities reported in Figure $6 \mathrm{a}-\mathrm{c}$. These graphs show the emissivity variations in $19-37 \mathrm{GHz}$ space as a function of $r_{\text {near surf }}$ and $Q_{n}$. The black curve corresponds to homogeneous snowpacks, i.e. $Q_{n}=0$, with $r_{\text {near surf }}$ ranging from 0.1 to $1 \mathrm{~mm}$. Each red dashed curve corresponds to an increasing grain-size gradient, $Q_{n}$, for a given value of $r_{\text {near surf }}$. The figures show that for increasing $Q_{n}$ the departure from the homogeneous snowpack curve increases, and the difference between the emissivity at 19.3 and $37 \mathrm{GHz}$ decreases. The difference can decrease to become null (i.e. to represent a flat spectrum at the intersection between the red curves and the $1: 1$ line) and can even be negative (i.e. to represent an 'anomalous' spectrum when the red dashed curves are above the $1: 1$ line) for $n=1$ and 2 only.

In addition and most importantly, the region covered by the red curves overlaps the space of the observations for $n=1$ and 2 only (Fig. $6 a$ and b). This means that a linear increase in grain radius with increasing depth $(n=1$; Fig. 6a) or in the grain surface area $(n=2$; Fig. $6 b)$ is able to explain nearly all observed emissivities over Antarctica, whereas a linear increase in the snow grain volume $(n=3$; Fig. 6c), as suggested by Zwally (1977), is able to explain a flat spectrum but not an 'anomalous' spectrum. Similar results are obtained with MEMLS and its correlation length parameter (not shown).

Using the simple parameterization of Equation (2) with either $n=1$ or 2 , there is a unique pair of snow grain-size

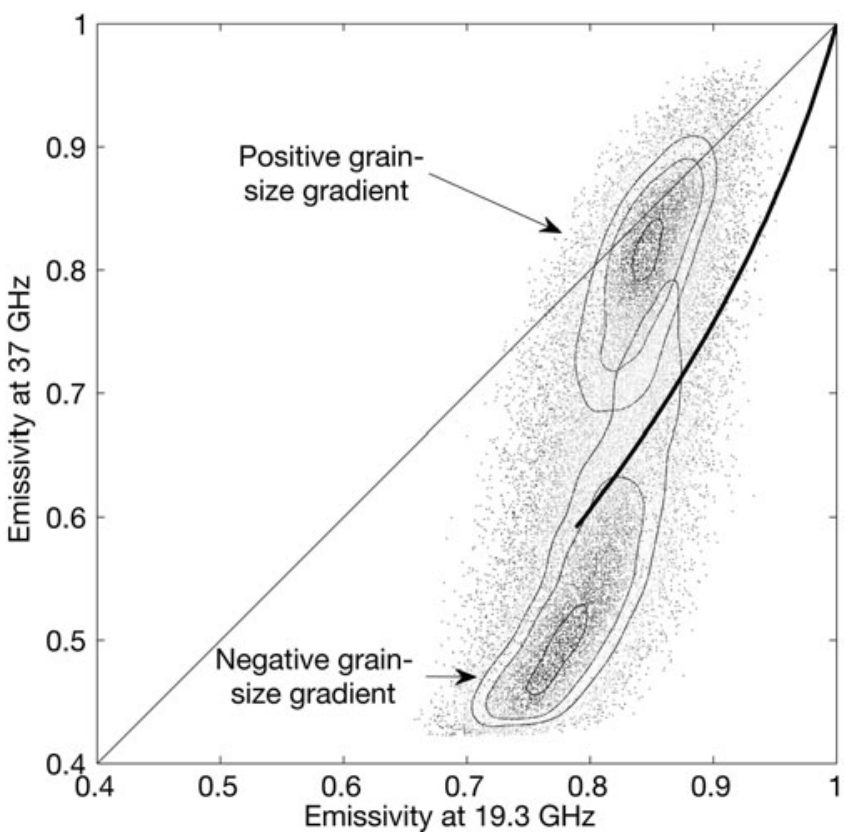

Fig. 5. Modeled vertically polarized emissivities for snowpacks with a fixed density $\left(350 \mathrm{~kg} \mathrm{~m}^{-3}\right)$ and random variations of snow grain radius. Snowpacks were classified in two categories depending on whether the grain size increased or decreased with depth, i.e. positive or negative grain-size gradient. Contour lines represent three levels of density dots for the two types of snow grain-size profiles. The curve represents the emissivity of homogeneous snowpacks (DMRT-ML calculation, density $350 \mathrm{~kg} \mathrm{~m}^{-3}$; Fig. 3).

profile parameters $\left(r_{\text {near surf, }} Q_{n}\right.$ ) for nearly every couple of emissivities observed at 37 and $19.3 \mathrm{GHz}$ in Antarctica. This property is used to map $r_{\text {near surf }}$ and $Q_{n}$ in the dry-snow zone given the observed emissivities. To do this in practice, we consider a linear increase of the grain surface area $(n=2)$; the snowpack has a constant temperature equal to the annual mean air temperature at the pixel location derived from ERA-40 and the density is $350 \mathrm{~kg} \mathrm{~m}^{-3}$. The retrieval works well except in regions where the emissivities are less than $\sim 0.70$, i.e. $1 \%$ of the dry-snow zone. This is due to the failure of the Rayleigh assumption for large grains used in DMRT-ML for the scattering computation. Moreover, although the retrieval works in heterogeneous regions (e.g. mountainous regions and blue ice areas; Bintanja, 1999; Winther and others, 2001), the retrieved profile parameters must be interpreted with caution in these areas.

Maps of snow grain radius near the surface, $r_{\text {near surf, }}$ and snow grain-size gradient, $Q_{2}$, are shown in Figure $7 a$ and $b$, respectively. The overall tendency is an increase of grain radius from the periphery of the continent towards the interior, especially towards the ridge of the East Antarctic plateau (Fig. 7a).

The snow grain-size gradient (Fig. 7b) presents more complex patterns. The gradient is nearly zero in Marie Byrd Land (in violet color). It is weakly positive near the coasts of Wilkes Land and Dronning Maud Land and increases southward up to the East Antarctic ridge. The Lambert Glacier basin presents a large gradient, and the largest gradients are found in East Antarctica in the regions south of the ridge near Dronning Maud Land and in Victoria Land. These areas are characterized by the lowest emissivities found in Antarctica (Fig. 1). 

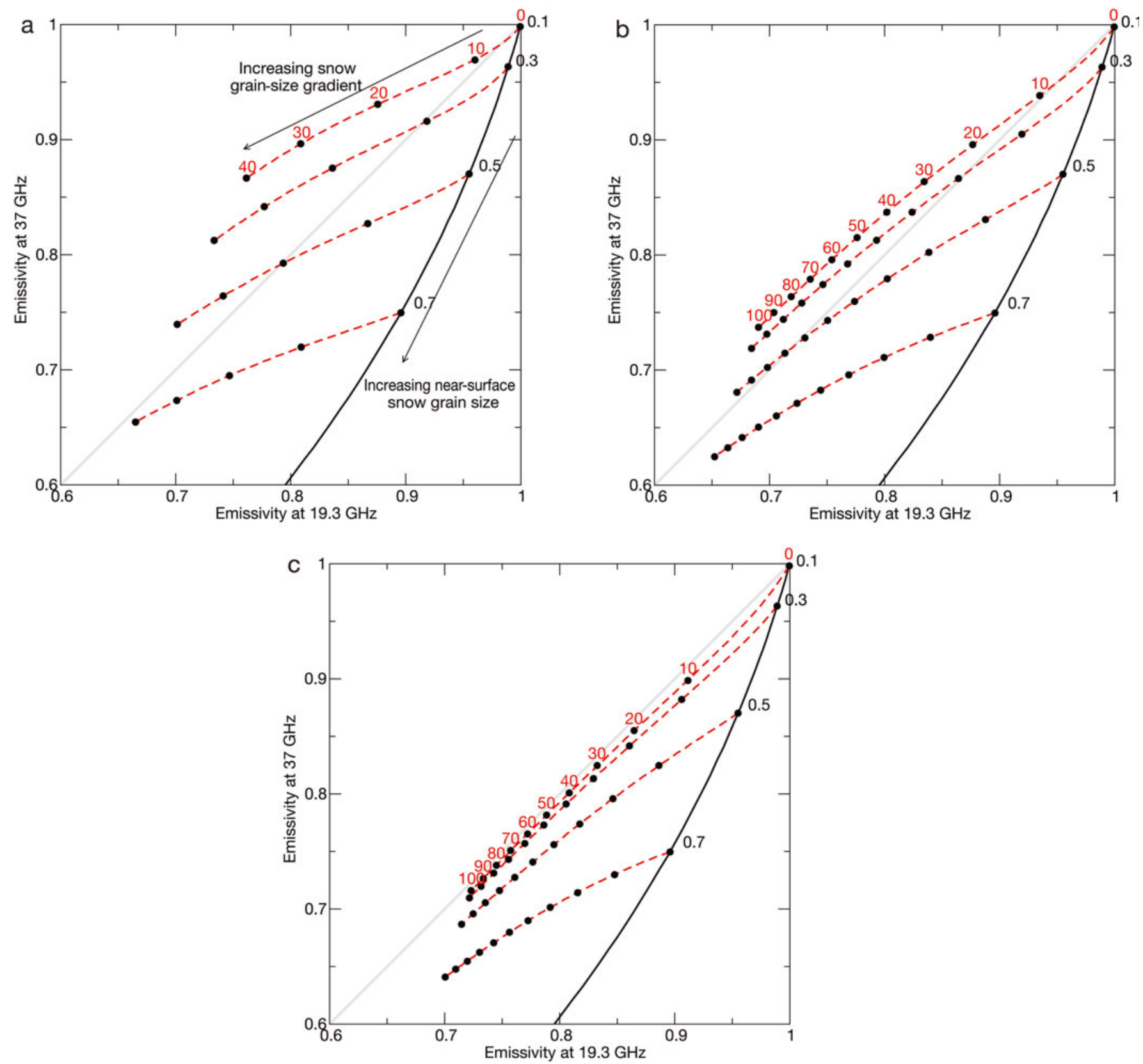

Fig. 6. Modeled emissivities of homogeneous snowpacks (black curve) and of snowpacks with a linear increase of (a) snow grain radius $(n=1)$, (b) grain surface area $(n=2)$ and (c) grain volume $(n=3)$. The dashed red curves represent an increase in the grain-size gradient for a given near-surface snow grain size (Equation (2)). Annotated values along the dashed curve are $Q_{n}\left(\mathrm{~m}^{2} \mathrm{~m}^{-1}\right)$ and along the homogeneous curve are the near-surface grain size $(\mathrm{mm})$.

\section{VALIDATIONS AND DISCUSSION}

The two important results found in section 3 are validated and discussed here. The first result is that the emissivity spectra observed in Antarctica are related to the increase in grain radius with increasing depth; the second result is that microwave observations at two frequencies provide a means to estimate the snow grain-size profile.

The growth of snow grains with increasing depth in Antarctica has been known for several years and has been reported by numerous workers (e.g. Stephenson, 1967; Gow, 1969; Koerner, 1971; Picciotto and others, 1971; Alley and others, 1982; Nishimura and Maeno, 1985; Alley, 1987; Alley and Bentley, 1988; Qin and others, 1988; Albert and others, 2000; Gay and others, 2002; Kärkäs and others, 2002; Gow and others, 2004; Rick and Albert, 2004). It is explained by a general trend of the metamorphism processes (e.g. temperature gradient) promoting the growth of larger grains at the expense of smaller grains (Colbeck, 1983). Over Antarctica, and in particular over the inland ice sheet, where several areas show very low snow accumulation, the seasonal cycle of temperature can act upon the upper layers of snow repeatedly, for up to centuries (e.g. Albert and others, 2004; Courville and others, 2007). This results in an increase in the mean grain size over time and, hence, over depth.

Quantitatively, a simple metamorphism theory (e.g. Gow, 1969) assumes a general linear increase in the grain surface area with time, $t$, such as

$$
r^{2}=r_{0}^{2}+K t
$$

where $r_{0}$ is the initial grain radius and $K$ is the grain growth 

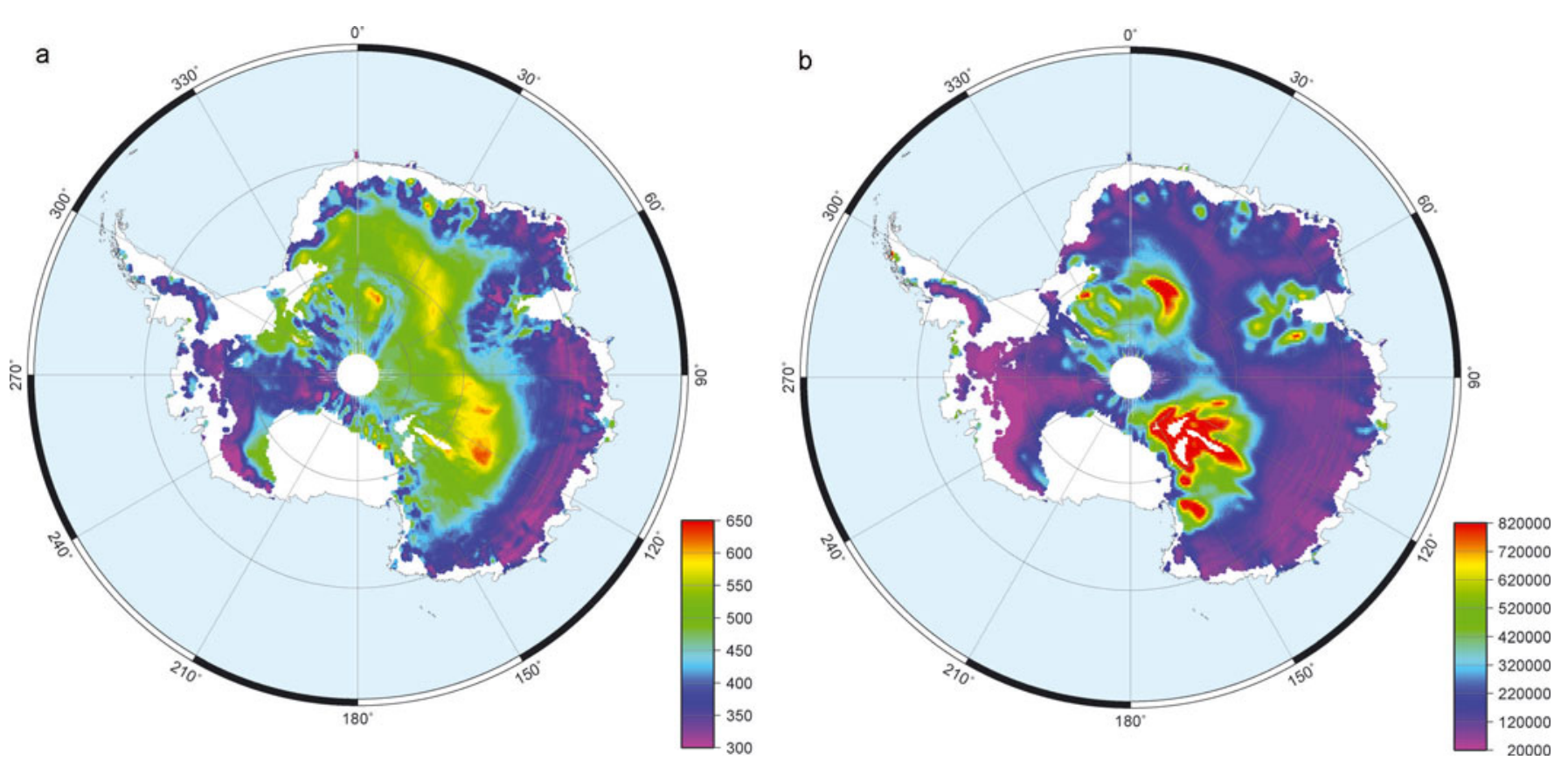

Fig. 7. Maps of (a) the near-surface grain radius, $r_{\text {near surf }}(\mu \mathrm{m})$ and (b) the grain-size vertical gradient, $Q_{2}\left(\mu \mathrm{m}^{2} \mathrm{~m}^{-1}\right)$, in the Antarctic dry zones derived from the 19.3 and $37 \mathrm{GHz}$ vertically polarized emissivities.

rate. By assuming, in addition, that the snow accumulation is constant over time and the densification is negligible, Equation (3) is equivalent to the snow grain-radius profile used in the present study, i.e. Equation (2) with the exponent $n=2$.

It was shown, by generating a snow grain network and analyzing its evolution using a Monte Carlo method, that a more general law is possible (Anderson and others, 1984; Srolovitz and others, 1984):

$$
r^{n}=r_{0}^{n}+K t
$$

In Equation (4), the growth exponents $n<2$ were excluded (Anderson and others, 1984; Srolovitz and others, 1984). This excludes the case $n=1$ which is, however, compatible with the observed emissivities.

In addition, with the observed emissivities, we found that $n=3$ is incompatible with the 'anomalous' snow spectra observed in some regions. We thus favor $n=2$ and use this value for the quantitative estimation of the profile parameters. The following subsections attempt a comparison of our retrieved grain-radius profiles with measurements and previous estimates from satellite data.

\subsection{Comparison with in-situ measurements}

Comparison of the retrieved profiles (i.e. the near-surface snow grain radius and the gradient) with ground measurements is difficult because of representativeness issues. The scale of measurements in a snow pit is very different from the $S S M / I$ pixel $(25 \mathrm{~km} \times 25 \mathrm{~km})$. Moreover, grain size measured by visual inspection and/or photography is quantified by diverse dimensions (e.g. the maximum dimension of the prevalent grains (Colbeck and others, 1990), axis length, eccentricities and mean convex radii (Gay and others, 2002)). These are sometimes subjective, although the grain size observed in microwave remote sensing is also not clearly defined (e.g. Mätzler, 2002).
For these two reasons at least, a detailed and quantitative analysis is impossible. Nevertheless, we provide here a broad comparison with in situ measurements acquired along traverses, as the same method was used over a wide distance and therefore presents consistency in space. Most of these data are summarized by Surdyk and Fily (1993).

Between McMurdo $\left(78^{\circ} \mathrm{S}, 154.2^{\circ} \mathrm{E}\right)$ and the South Pole, large grains were observed near the surface and very large grains were observed at $\sim 2 \mathrm{~m}$ depth (Giovinetto, 1963). In these regions, the retrieved profiles also present large grains near the surface (Fig. 7a) and the largest snow grain-size gradients found in Antarctica (Fig. 7b).

In Wilkes Land, along the $69^{\circ} \mathrm{S}$ parallel, grain sizes were reported to be fairly constant between 112 and $131^{\circ} \mathrm{E}$, and grain growth between the surface and $2 \mathrm{~m}$ depth was weak (Goodwin, 1988; Surdyk and Fily, 1993). The Wilkes Land profiles retrieved by satellite agree with these characteristics; the gradient is weak and the grain radius near the surface is moderate.

Between Mirny $\left(66.55^{\circ} \mathrm{S}, 93.02^{\circ} \mathrm{E}\right)$ and Vostok $\left(78.48^{\circ} \mathrm{S}\right.$, $\left.106.82^{\circ} \mathrm{E}\right)$, the grain sizes near the surface are small and almost constant along the traverse. This disagrees with the retrieved near-surface grain sizes, which increase from the coast to the plateau. In addition, grain size measured at $2 \mathrm{~m}$ depth grows from the coast to the plateau. Therefore, owing to the almost constant grain size near the surface, an increase in the snow grain-size gradient is measured from the coast towards the plateau. Such a trend is observed by satellite (Fig. 7b).

In the Lambert Glacier basin, depth hoar (large grains) was measured over a wide zone south of $73^{\circ} \mathrm{S}$ (Higham and Craven, 1997). There are depth-hoar layers in the near surface and some pervasive layers over a few meters, creating large gradients in grain size. Retrieved snow-profile properties agree well with these observations.

In the megadune region $\left(120-150^{\circ} \mathrm{E}\right.$ and south of $\left.75^{\circ} \mathrm{S}\right)$, measurements show a strong increase in grain size with 
increasing depth (Albert and others, 2004; Courville and others, 2007) and agree well with the satellite observations (Fig. 7b). Note that in this area the grain sizes are so large that the DMRT-ML calculation may fail. In practice, the maximum size is $\sim 1.3 \mathrm{~mm}$ for calculations at $19.3 \mathrm{GHz}$ (excluding emissivities less than $\sim 0.7$ ). These areas are shown in white in Figure 7.

These comparisons with measured grain size along several traverses are qualitative but indicate that spatial variations of the retrieved snow grain properties are generally realistic in East Antarctica.

\subsection{Comparison with another dataset of snow grain size retrieved by satellite}

The comparison with snow grain size retrieved by visible and infrared satellite sensors is technically easier because the spatial coverage is similar. However, there is no agreement between retrieved snow grains in the microwave range and in the solar spectrum. In particular, a general decrease in surface snow grain size from the coast towards the East Antarctic plateau is observed with the sensor Polarization and Directionality of the Earth's Reflectances (POLDER; Mondet, 1999), the Along Track Scanning Radiometer (ATSR-2; Mondet, 1999), the Landsat Thematic Mapper (Bourdelles and Fily, 1993) and the Moderate Resolution Imaging Spectroradiometer (MODIS; Scambos and others, 2007). Our results show the opposite trend.

This apparent discrepancy may be explained by the large difference of penetration depths between the microwave range and the solar spectrum. In the near-infrared, which is typically used to estimate surface snow grain size, the penetration is several centimeters. In contrast, microwaves at $37 \mathrm{GHz}$ penetrate an order of magnitude deeper. Although we consider profiles with a theoretical grain radius at the surface called 'the near-surface grain radius', this parameter is actually representative of the first few decimeters. Hence, microwave sensors sense snow that has already experienced metamorphism for several months near coasts and for at least 1 or 2 years on the plateau, whereas infrared sensors sense freshly fallen snow.

This explanation is confirmed when considering the two layers of retrieved snow grain size using MODIS (Jin and others, 2008). The study shows a high temporal variation in surface snow grain size and unclear spatial patterns. Furthermore, the grain size retrieved in the bottom layer (below $5 \mathrm{~mm}$ ), in particular, always appears smaller near the coast than in the interior of the continent (Jin and others, 2008, fig. 9). This specific point is in agreement with our microwave observations. However, this interpretation is difficult because the retrieval is based on one observation per month and limited by the presence of clouds.

\subsection{Comparison with grain size estimated by snow metamorphism theory and driven by climatic data}

Microwave emission senses snow at depth and thus is likely to have undergone extensive metamorphism due to temperature-gradient metamorphism (Li and Zwally, 2004). Therefore, it is worth considering complex thermodynamic snow models (e.g. Crocus; Brun and others, 1992) to calculate the grain size, and especially the vertical gradient of grain size. Here we consider a simple calculation that assumes (1) the grain growth rate depends on the air temperature in the form of an Arrhenius-type relationship (Colbeck, 1991; Brun and others, 1992) and (2) the age of a grain is linearly related to its depth and the snow accumulation rate. Hence, the vertical gradient of grain size, $Q^{\text {clim, }}$ is computed from climatic data as:

$$
Q^{\mathrm{clim}}=\frac{K_{0} \mathrm{e}^{\frac{-E}{R T}}}{\pi A}
$$

where $T$ is the mean annual air temperature, $A$ is the mean annual snow accumulation $\left(\mathrm{mm} \mathrm{a}^{-1}\right), R$ is the gas constant $\left(8.314 \mathrm{~J} \mathrm{~mol}^{-1} \mathrm{~K}^{-1}\right), E$ is the activation energy (here equal to $48570 \mathrm{~J} \mathrm{~mol}^{-1}$; Gow, 1969) and $K_{0}$ is a constant rate established for isothermal crystal growth (equal to $6.75 \times 10^{7} \mathrm{~mm}^{2} \mathrm{a}^{-1}$; Gow, 1969; Alley and others, 1982). We apply Equation (5) and its constants to grain kinetic growth conditions.

The temperature, $T$, and snow accumulation rate, $A$, are extracted from climate model calculations. To avoid modelspecific results, we consider two different models, (1) the Modèle Atmosphérique Régional (MAR) (Gallée and Schayes, 1994; Gallée, 1995) based on a detailed physical representation of the polar meteorological processes (Gallée and others, 2001) with spatial resolution $40 \mathrm{~km}$ and (2) the general circulation model LMDZ4 (Hourdin and others, 2006) with a grid zoomed over Antarctica, to a resolution of $60 \mathrm{~km}$ (Krinner and Genthon, 1997; Krinner and others, 2007).

The maps of $Q^{\text {clim }}$ obtained from both models are presented in Figure 8. Comparisons with the retrieved grain-size gradient, $Q_{2}$ (Fig. 7b), show similar spatial variations. In particular, low values of the grain-size gradient (i.e. nearly homogeneous snowpacks) are observed in Mary Byrd Land in all the maps. Comparable spatial trends are also observed from Dronning Maud Land to Wilkes Land following the ridge. Patterns located in Dronning Maud Land, in Victoria Land and in regions south of the FilchnerRonne Ice Shelf $\left(300-330^{\circ} \mathrm{E}\right)$ are predicted by MAR and retrieved with the microwave radiometers, but the magnitude and the precise location are slightly different. Both maps (Figs $7 \mathrm{~b}$ and 8 ) show strong gradients of grain radius in the Lambert Glacier basin $\left(70^{\circ} \mathrm{S}, 60^{\circ} \mathrm{E}\right)$ and south of Talos Dome (area near $80^{\circ} \mathrm{S}, 160^{\circ} \mathrm{E}$ ). We notice that the snow megadune region in Dronning Maud Land is wider with the microwave retrievals than with MAR. In addition, some discrepancies are visible over the drainage basins in the Transantarctic Mountains where microwave measurements are likely to be inaccurate due to the presence of mixed pixels (rock and snow) and complex topography.

The same general patterns are predicted by the LMDZ4 model (Fig. 8b). However, the region of weak gradients located between Marie Byrd Land and the South Pole has a lower extent than that retrieved by microwave measurements. Moreover, the position and the extent of the area with large gradients in Dronning Maud Land are different.

The magnitude of the snow grain-size gradient retrieved by microwave observations is different from the prediction using climate models. This is probably explained by the use of constants $K_{0}$ and $E$ in the case of growth dominated by the temperature gradient instead of isothermal conditions. Indeed, very large variations of $K_{0}$, up to a factor of 60 , have been measured in Antarctica (Arnaud, 1997).

As a whole and given the strong assumptions, the spatial variations of grain-size gradients computed with an Arrhenius-type relationship and climatic data present 

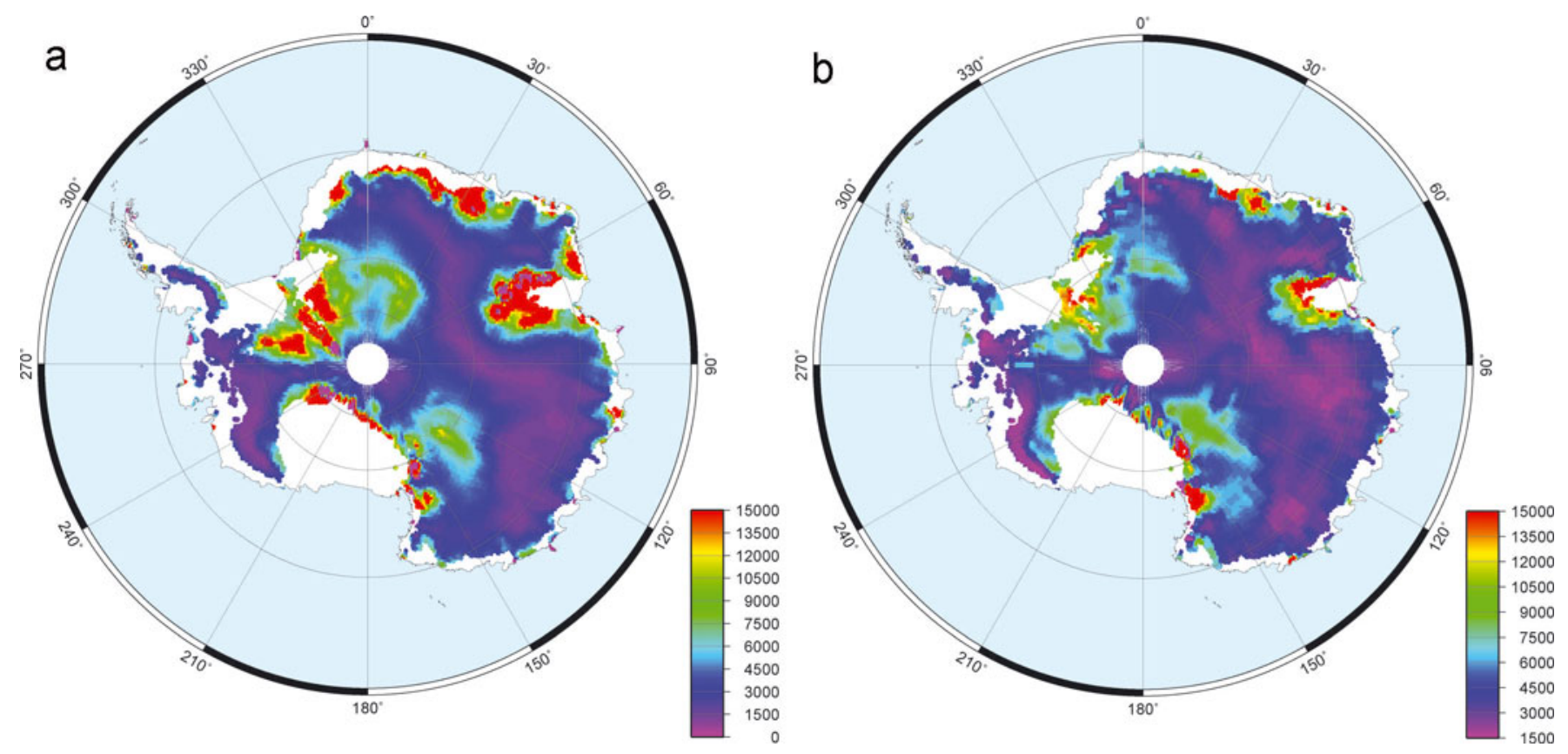

Fig. 8. Map of the gradient of grain size, $Q^{\text {clim }}\left(\mu \mathrm{m}^{2} \mathrm{~m}^{-1}\right)$, deduced from metamorphism theory (Equation (5)) using climatic data from (a) the MAR model and (b) the LMDZ4 model.

reasonable agreement with those estimated from microwave observations.

\section{CONCLUSIONS}

We have examined the vertically polarized microwave emissivity in the Antarctic dry-snow zones at 19.3 and $37 \mathrm{GHz}$. In contrast with most dry-snow covered areas on Earth, the emissivities in Antarctica at 19.3 and $37 \mathrm{GHz}$ are nearly equal. A weak frequency dependence, considered here as a flat spectrum, results from the heterogeneity of the Antarctic snowpack in the first few meters depth and from the fact that the Antarctic snowpack can be considered semi-infinite, even at $19 \mathrm{GHz}$, contrary to seasonal snowpacks. More precisely, using a multilayered electromagnetic model (DMRT-ML) and different methodologies to construct snowpacks, we show that an increase in snow grain radius with depth is the most realistic snowpack structure able to explain the observed emissivities, and in particular the flat spectrum. Neither homogeneous snowpacks nor vertical variations of the snow density lead to emissivities comparable with the observations. Many in situ measurements confirm that grain size increases with depth, but the fact that this is a necessary condition to explain the microwave emissivities everywhere in Antarctica (at least in the dry zones) is new.

Next, assuming that the snow grain profile follows a simple analytical relationship, we were able to retrieve two parameters of the profile from the observed emissivities at 19.3 and $37 \mathrm{GHz}$ : the near-surface grain radius (representative of the grain radius in the top few decimeters) and the vertical gradient of the grain radius. Validation of the retrieval is difficult, but we show a general agreement between the spatial variations of the retrieved parameters and in situ measurements of grain size along various traverses in East Antarctica. The retrieved snow grain-size gradient patterns are also in agreement with the grain growth rate computed with an Arrhenius-type relationship and modeled climatic variables governing the snow metamorphism. However, the comparison with grain size estimated by spaceborne sensors in the solar spectrum (e.g. MODIS) shows very large discrepancies. We explain these in terms of the difference in sensing depth between the sensors.

The present study is limited to 19.3 and $37 \mathrm{GHz}$ observations at vertical polarization, which provide, in the first meters of the snowpack only, information on the grain radius. In the future it might be possible to characterize the grain radius profile at a greater depth (typically tens of meters) by including additional observations at lower frequencies available from the Advanced Microwave Scanning Radiometer (AMSR-E, 6.9 and $10.7 \mathrm{GHz}$ ) or the Soil Moisture and Ocean Salinity (SMOS) radiometer $(1.4 \mathrm{GHz})$. Moreover, the addition of the horizontally polarized emissivities should provide information on the density profile and especially the vertical variability of the density. Also, the retrieved snow grain-size profile parameters we have presented could be used to investigate other glaciological properties.

An open question is how our method extends to regions with seasonal snowpack where the presence of underlying ground or ice (in the case of snow-covered sea ice) is important for the emissivity spectrum, in particular at $19 \mathrm{GHz}$ and lower frequencies.

\section{ACKNOWLEDGEMENTS}

This work was funded by the French remote-sensing program, Programme National de Télédétection Spatial (CNRS-CNES), the ANR-07-VULN-013 VANISH project of the Agence Nationale de la Recherche and the LEFE INSUCNRS (NIEVE) program. We thank $H$. Gallée and G. Krinner for providing the climate model data, C. Mätzler for the MEMLS code and his reviewing work, and an anonymous referee. 


\section{REFERENCES}

Albert, M.R., E.F. Shultz and F.E. Perron, Jr. 2000. Snow and firn permeability at Siple Dome, Antarctica. Ann. Glaciol., 31, 353-356.

Albert, M., C. Shuman, Z. Courville, R. Bauer, M. Fahnestock and T. Scambos. 2004. Extreme firn metamorphism: impact of decades of vapor transport on near-surface firn at a lowaccumulation glazed site on the East Antarctic plateau. Ann. Glaciol., 39, 73-78.

Alley, R.B. 1987. Texture of polar firn for remote sensing. Ann. Glaciol., 9, 1-4.

Alley, R.B. 1988. Concerning the deposition and diagenesis of strata in polar firn. J. Glaciol., 34(118), 283-290.

Alley, R.B. and C.R. Bentley. 1988. Ice-core analysis on the Siple Coast of West Antarctica. Ann. Glaciol., 11, 1-7.

Alley, R.B., J.F. Bolzan and I.M. Whillans. 1982. Polar firn densification and grain growth. Ann. Glaciol., 3, 7-11.

Anderson, M.P., D.J. Srolovitz, G.S. Grest and P.S. Sahni. 1984. Computer simulation of grain growth. I. Kinetics. Acta Metall. Mater., 32(5), 783-791.

Arnaud, L. 1997. Modélisation de la transformation de la neige en glace à la surface des calottes polaires: étude du transport des gaz dans ces milieux poreux. (Thèse de doctorat, Université Joseph Fourier, Grenoble.)

Arthern, R.J., D.P. Winebrenner and D.G. Vaughan. 2006. Antarctic snow accumulation mapped using polarization of $4.3 \mathrm{~cm}$ wavelength microwave emission. J. Geophys. Res., 111(D6), D06107. (10.1029/2004JD005667.)

Bintanja, R. 1999. On the glaciological, meteorological and climatological significance of Antarctic blue ice areas. Rev. Geophys., 37(3), 337-359.

Bourdelles, B. and M. Fily. 1993. Snow grain-size determination from Landsat imagery over Terre Adélie, Antarctica. Ann. Glaciol., 17, 86-92.

Bromwich, D.H. and R.L. Fogt. 2004. Strong trends in the skill of the ERA-40 and NCEP NCAR reanalyses in the high and midlatitudes of the southern hemisphere. J. Climate, 17(23), 4603-4619.

Brucker, L., and 6 others, In press. Modeling time series of microwave brightness temperature at Dome C, Antarctica, using vertically resolved snow temperature and microstructure measurements, J. Glaciol.

Brun, E., P. David, M. Sudul and G. Brunot. 1992. A numerical model to simulate snow-cover stratigraphy for operational avalanche forecasting. J. Glaciol., 38(128), 13-22.

Colbeck, S.C. 1983. Theory of metamorphism of dry snow. J. Geophys. Res., 88(C9), 5475-5482.

Colbeck, S.C. 1991. The layered character of snow covers. Rev. Geophys., 29(1), 81-96.

Colbeck, S.C. and 7 others. 1990. The international classification for seasonal snow on the ground. Wallingford, Oxon, Association of Scientific Hydrology. International Commission on Snow and Ice.

Comiso, J.C. 2000. Variability and trends in Antarctic surface temperatures from in situ and satellite infrared measurements. J. Climate, 13(10), 1674-1696.

Comiso, J.C., H.J. Zwally and J.L. Saba. 1982. Radiative transfer modeling of microwave emission and dependence on firn properties. Ann. Glaciol., 3, 54-58.

Courville, Z.R., M.R. Albert, M.A. Fahnestock, L.M. Cathles and C.A. Shuman. 2007. Impacts of an accumulation hiatus on the physical properties of firn at a low-accumulation polar site. J. Geophys. Res., 112(F2), F02030. (10.1029/2005JF000429.)

Fahnestock, M.A., T.A. Scambos, C.A. Shuman, R.J. Arthern, D.P. Winebrenner and R. Kwok. 2000. Snow megadune fields on the East Antarctic Plateau: extreme atmosphere-ice interaction. Geophys. Res. Lett., 27(22), 3719-3722.

Frezzotti, M., S. Gandolfi, F. La Marca and S. Urbini. 2002a. Snow dunes and glazed surfaces in Antarctica: new field and remotesensing data. Ann. Glaciol., 34, 81-88.
Frezzotti, M., S. Gandolfi and S. Urbini. 2002b. Snow megadunes in Antarctica: sedimentary structure and genesis. J. Geophys. Res., 107(D18), 4344. (10.1029/2001JD000673.)

Gallée, H. 1995. Simulation of the mesocyclonic activity in the Ross Sea, Antarctica. Mon. Weather Rev., 123(7), 2051-2069.

Gallée, H. and G. Schayes. 1994. Development of a threedimensional meso- $\gamma$ primitive equation model: katabatic winds simulation in the area of Terra Nova Bay, Antarctica. Mon. Weather Rev., 122(4), 671-685.

Gallée, H., G. Guyomarc'h and E. Brun. 2001. Impact of snowdrift on the Antarctic ice sheet surface mass balance: possible sensitivity to snow-surface properties. Bound.-Layer Meteorol., 99(1), 1-19.

Gay, M., M. Fily, C. Genthon, M. Frezzotti, H. Oerter and J.G. Winther. 2002. Snow grain-size measurements in Antarctica. J. Glaciol., 48(163), 527-535.

Giovinetto, M.B. 1963. Glaciological studies on the McMurdoSouth Pole traverse, 1960-1961. Inst. Polar Stud. Rep. 7.

Goodwin, I.D. 1988. Firn core data from shallow drilling investigations in eastern Wilkes Land, East Antarctica. ANARE Res. Notes 65.

Gow, A.J. 1969. On the rates of growth of grains and crystals in South Polar firn. J. Glaciol., 8(53), 241-252.

Gow, A.J., D. Meese and R. Bialas. 2004. Accumulation variability, density profiles and crystal growth trends in ITASE firn and ice cores from West Antarctica. Ann. Glaciol., 39, 101-109.

Grody, N. 2008. Relationship between snow parameters and microwave satellite measurements: theory compared with Advanced Microwave Sounding Unit observations from 23 to $150 \mathrm{GHz}$. J. Geophys. Res., 113(D22), D22108. (10.1029/ 2007JD009685.)

Grody, N.C. and A.N. Basist. 1997. Interpretation of SSM/I measurements over Greenland. IEEE Trans. Geosci. Remote Sens., 35(2), 360-366.

Higham, M. and M. Craven. 1997. Surface mass balance and snow surface properties from the Lambert Glacier basin traverses 1990-94. Hobart, Cooperative Research Centre for the Antarctic and Southern Ocean.

Hollinger, J.P., J.L. Pierce and G.A. Poe. 1990. SSM/I instrument evaluation. IEEE Trans. Geosci. Remote Sens., 28 (5), 781-790.

Hourdin, F. and 13 others. 2006. The LMDZ4 general circulation model: climate performance and sensitivity to parametrized physics with emphasis on tropical convection. Climate Dyn., 27(7-8), 787-813.

Jin, Y.-Q. 1994. Electromagnetic scattering modelling for quantitative remote sensing. Singapore, World Scientific.

Jin, Z., T.P. Charlock, P. Yang, Y. Xie and W. Miller. 2008. Snow optical properties for different particle shapes with application to snow grain size retrieval and MODIS/CERES radiance comparison over Antarctica. Remote Sens. Environ., 112(9), 3563-3581.

Kärkäs, E., H.B. Granberg, K. Kanto, K. Rasmus, C. Lavoie and M. Leppäranta. 2002. Physical properties of the seasonal snow cover in Dronning Maud Land, East Antarctica. Ann. Glaciol., 34, 89-94.

Koenig, L.S., E.J. Steig, D.P. Wienbrenner and C.A. Shuman. 2007. A link between microwave extinction length, firn thermal diffusivity, and accumulation rate in West Antarctica. J. Geophys. Res., 112(F3), F03018.

Koerner, R.M. 1971. A stratigraphic method of determining the snow accumulation rate at Plateau Station, Antarctica, and application to South Pole-Queen Maud Land Traverse 2, 19651966. In Crary, A.P., ed. Antarctic snow and ice studies II. Washington, DC, American Geophysical Union, 225-238.

Krinner, G. and C. Genthon. 1997. The Antarctic surface mass balance in a stretched grid general circulation model. Ann. Glaciol., 25, 73-78.

Krinner, G., B. Guichard, K. Ox, C. Genthon and O. Magand. 2007. Influence of oceanic boundary conditions in simulations of Antarctic climate and surface mass balance change during the coming century. J. Climate, 21(5), 938-962. 
Lemke, P. and 10 others. 2007. Observations: changes in snow, ice and frozen ground. In Solomon, S. and 7 others, eds. Climate change 2007: the physical science basis. Contribution of Working Group I to the Fourth Assessment Report of the Intergovernmental Panel on Climate Change. Cambridge, etc., Cambridge University Press, 337-383.

Li, J. and H.J. Zwally. 2004. Modeling the density variation in the shallow firn layer. Ann. Glaciol., 38, 309-313.

Liang, D., K. Tse, Y. Tan, L. Tsang and K.H. Ding. 2006. Scattering and emission in snow based on QCA/DMRT and Numerical Maxwell Model of 3Dimensional simulations (NMM3D). In Proceedings of the IEEE 9th Specialist Meeting on Microwave Radiometry and Remote Sensing of the Environment (MicroRad 2006), 28 February-3 March 2006, San Juan, Puerto Rico. Piscataway, NJ, Institute of Electrical and Electronics Engineers, 197-202.

Liang, D., X. Xu, L. Tsang, K.M. Andreadis and E.G. Josberger. 2008. The effects of layers in dry snow on its passive microwave emissions using dense media radiative transfer theory based on the quasicrystalline approximation (QCA/DMRT). IEEE Trans. Geosci. Remote Sens., 46 (11), 3663-3671.

Long, D.G. and M.R. Drinkwater. 2000. Azimuth variation in microwave scatterometer and radiometer data over Antarctica. IEEE Trans. Geosci. Remote Sens., 38(4), 1857-1870.

Macelloni, G., S. Paloscia, P. Pampaloni and M. Tedesco. 2001. Microwave emission from dry snow: a comparison of experimental and model result. IEEE Trans. Geosci. Remote Sens., 39(12), 2649-2656.

Macelloni, G., M. Brogioni, P. Pampaloni and A. Cagnati. 2007. Multifrequency microwave emission from the Dome-C area on the East Antarctic plateau: temporal and spatial variability. IEEE Trans. Geosci. Remote Sens., 45(7), 2029-2039.

Magand, O., G. Picard, L. Brucker, M. Fily and C. Genthon. 2008. Snow melting bias in microwave mapping of Antarctic snow accumulation. Cryosphere, 2(2), 109-115.

Mätzler, C. 1994. Passive microwave signatures of landscapes in winter. Meteorol. Atmos. Phys., 54(1-4), 241-260.

Mätzler, C. 1998. Improved Born approximation for scattering in a granular medium. J. Appl. Phys., 83(11), 6111-6117.

Mätzler, C. 2002. Relation between grain-size and correlation length of snow. J. Glaciol., 48(162), 461-466.

Mätzler, C. and E. Schanda. 1982. Towards the definition of optimum sensor specifications for microwave remote sensing of snow. IEEE Trans. Geosci. Remote Sens., 20(1), 57-66.

Mätzler, C. and A. Wiesmann. 1999. Extension of the microwave emission model of layered snowpacks to coarse-grained snow. Remote Sens. Environ., 70(3), 317-325.

Mätzler, C., R.O. Ramseier and E. Svendsen. 1984. Polarization effects in sea-ice signatures. IEEE J. Ocean. Eng., 9(5), 333-338.

Mondet, J. 1999. Étude des paramètres de surface de la calotte polaire antarctique, dans les domaines spectraux du visible et du proche infrarouge, à partir des donnés de l'instrument de télédétection POLDER. (Thèse de doctorat, Université Joseph Fourier, Grenoble.)

Nishimura, H. and N. Maeno. 1985. Studies on structures and physical properties of snow on Mizuho Plateau, Antarctica. Ann. Glaciol., 6, 105-107.

Picard, G. and M. Fily. 2006. Surface melting observations in Antarctica by microwave radiometers: correcting 26-year time series from changes in acquisition hours. Remote Sens. Environ. 104(3), 325-336.

Picard, G., M. Fily and H. Gallée. 2007. Surface melting derived from microwave radiometers: a climatic indicator in Antarctica. Ann. Glaciol., 46, 29-34.

Picard, G., L. Brucker, M. Fily, H. Gallée and G. Krinner. 2009. Modeling time series of microwave brightness temperature in Antarctica. J. Glaciol., 55(191), 537-551.

Picciotto, E., G. Crozaz and W. De Breuck. 1971. Accumulation on the South Pole-Queen Maud Land traverse, 1964-1968. In Crary, A.P., ed. Antarctic snow and ice studies II. Washington, DC, American Geophysical Union, 257-315.
Prigent, C., J.-P. Wigneron, W.B. Rossow and J.R. Pardo-Carrion. 2000. Frequency and angular variations of land surface microwave emissivities: can we estimate SSM/T and AMSU emissivities from SSM/I emissivities? IEEE Trans. Geosci. Remote Sens., 38(5), 2373-2386.

Qin, D., N.W. Young and R.J. Thwaites. 1988. Growth rate of crystals within the surface-snow/firn layer in Wilkes Land, East Antarctica. Ann. Glaciol., 11, 121-125.

Rémy, F. and J.F. Minster. 1991. A comparison between active and passive microwave measurements of the Antarctic ice sheet and their association with the surface katabatic winds. J. Glaciol., 37(125), 3-10.

Rick, U.K. and M.R. Albert. 2004. Microstructure and permeability in the near-surface firn near a potential US deep-drilling site in West Antarctica. Ann. Glaciol., 39, 62-66.

Rosenfeld, S. and N. Grody. 2000. Anomalous microwave spectra of snow cover observed from Special Sensor Microwave/lmager measurements. J. Geophys. Res., 105(D11), 14,913-14,925.

Rosenkranz, P.W. 1998. Water vapor microwave continuum absorption: a comparison of measurements and models. Radio Sci., 33(4), 919-928.

Scambos, T.A., T.M. Haran, M.A. Fahnestock, T.H. Painter and J. Bohlander. 2007. MODIS-based Mosaic of Antarctica (MOA) data sets: continent-wide surface morphology and snow grain size. Remote Sens. Environ., 111(2-3), 242-257.

Schneider, D.P. and E.J. Steig. 2002. Spatial and temporal variability of Antarctic ice sheet microwave brightness temperatures. Geophys. Res. Lett., 29(20), 1964. (10.1029/2002GL015490.)

Schneider, D.P., E.J. Steig and J.C. Comiso. 2004. Recent climate variability in Antarctica from satellite-derived temperature data. J. Climate, 17(7), 1569-1583.

Sherjal, I. and M. Fily. 1994. Temporal variations of microwave brightness temperatures over Antarctica. Ann. Glaciol., 20, $19-25$.

Shuman, C.A. and C.R. Stearns. 2001. Decadal-length composite inland West Antarctic temperature records. J. Climate, 14(9), 1977-1988.

Shuman, C.A., R.B. Alley and S. Anandakrishnan. 1993. Characterization of a hoar-development episode using SSM/I brightness temperatures in the vicinity of the GISP2 site, Greenland. Ann. Glaciol., 17, 183-188.

Shuman, C.A. and J.C. Comiso. 2002. In situ and satellite surface temperature records in Antarctica. Ann. Glaciol., 34, 113-120.

Srolovitz, D.J., M.P. Anderson, P.S. Sahni and G.S. Grest. 1984. Computer simulation of grain growth. II. Grain size distribution, topology, and local dynamics. Acta Metall. Mater., 32(5), 793-802.

Steig, E.J., D.P. Schneider, S.D. Rutherford, M.E. Mann, J.C. Comiso and D.T. Shindell. 2009. Warming of the Antarctic ice-sheet surface since the 1957 International Geophysical Year. Nature, 457(7228), 459-462.

Stephenson, P.J. 1967. Some considerations of snow metamorphism in the Antarctic ice sheet in the light of ice crystal studies. In Oura, H., ed. Physics of snow and ice. Sapporo, Hokkaido University Institute of Low Temperature Science, 725-740.

Stogryn, A. 1986. A study of the microwave brightness temperature of snow from the point of view of the strong fluctuation theory. IEEE Trans. Geosci. Remote Sens., 24(2), 220-231.

Surdyk, S. 2002. Using microwave brightness temperature to detect short-term surface air temperature changes in Antarctica: an analytical approach. Remote Sens. Environ., 80(2), 256-271.

Surdyk, S. and M. Fily. 1993. Comparison of the passive microwave spectral signature of the Antarctic ice sheet with ground traverse data. Ann. Glaciol., 17, 161-166.

Surdyk, S. and M. Fily. 1995. Results of a stratified snow emissivity model based on the wave approach: application to the Antarctic ice sheet. J. Geophys. Res., 100(C5), 8837-8848.

Tedesco, M. and J.R. Wang. 2006. Atmospheric correction of AMSR-E brightness temperatures for dry snow cover mapping. IEEE Geosci. Remote Sens. Lett., 3(3), 320-324. 
Tedesco, M. and 7 others. 2006. Comparison of local scale measured and modelled brightness temperatures and snow parameters from the CLPX 2003 by means of a dense medium radiative transfer theory model. Hydrol. Process., 20(4), 657-672.

Tsang, L. and J.A. Kong. 2001. Scattering of electromagnetic waves: advanced topics. New York, Wiley.

Tsang, L., C.T. Chen, A.T.C. Chang, J. Guo and K.H. Ding. 2000a. Dense media radiative transfer theory based on quasicrystalline approximation with application to passive microwave remote sensing of new snow. Radio Sci., 35(3), 731-749.

Tsang, L., J.A. Kong and K.-H. Ding. 2000b. Scattering of electromagnetic waves: theories and applications. New York, Wiley.

Tsang, L., J. Pan, D. Liang, Z. Li, D.W. Cline and T. Tan. 2007. Modeling active microwave remote sensing of snow using dense media radiative transfer (DMRT) theory with multiple-scattering effects. IEEE Trans. Geosci. Remote Sens., 45(4), 990-1004.

Tsang, L., D. Liang, X. Xu and P. Xu. 2008. Microwave emission from snowpacks: modeling the effects of volume scattering, surface scattering and layering. In Proceedings of 10th Specialist Meeting on Microwave Radiometry and Remote Sensing of the Environment (MicroRad 2008), 11-14 March 2008, Firenze, Italy. Piscataway, NJ, Institute of Electrical and Electronics Engineers, 1-4.

Turner, J. and 8 others. 2005. Antarctic climate change during the last 50 years. Int. J. Climatol., 25, 279-294.
Uppala, S.M. and 45 others. 2005. The ERA-40 re-analysis. Q. J. $R$. Meteorol. Soc., 131(612), 2961-3212.

Vaughan, D.G., J.L. Bamber, M.B. Giovinetto, J. Russell and A.P.R. Cooper. 1999. Reassessment of net surface mass balance in Antarctica. J. Climate, 12(4), 933-946.

West, R., L. Tsang and P. Winebrenner. 1993. Dense medium radiative transfer theory for two scattering layers with a Rayleigh distribution of particle sizes. IEEE Trans. Geosci. Remote Sens., 31 (2), 426-437.

West, R.D., D.P. Winebrenner and L. Tsang. 1994. Influence of layering and grain size on microwave emission from polar firn. In Stein, T.I., ed. Proceedings of 14th International Geoscience and Remote Sensing Symposium (IGARSS '94), 8-12 August 1994, Pasadena, California, USA. Piscataway, NJ, Institute of Electrical and Electronics Engineers, 1297-1299.

West, R.D., D.P. Winebrenner, L. Tsang and H. Rott. 1996. Microwave emission from density-stratified Antarctic firn at $6 \mathrm{~cm}$ wavelength. J. Glaciol., 42(140), 63-76.

Wiesmann, A. and C. Mätzler. 1999. Microwave emission model of layered snowpacks. Remote Sens. Environ., 70(3), 307-316.

Winther, J.-G., M.N. Jespersen and G.E. Liston. 2001. Blue-ice areas in Antarctica derived from NOAA AVHRR satellite data. J. Glaciol., 47(157), 325-334.

Zwally, H.J. 1977. Microwave emissivity and accumulation rate of polar firn. J. Glaciol., 18(79), 195-215.

MS received 22 June 2009 and accepted in revised form 4 May 2010 